\title{
Islet-Cell Antibodies and HLA type in Japanese Insulin-Dependent Diabetics
}

\author{
TAKehiko SAKURAMI ${ }^{1}$, Kengo NAGAOKA ${ }^{1}$, Noboru NABEYA ${ }^{1}$, \\ Hiroo IMURA ${ }^{1}$ and SHotaro KUNO ${ }^{2}$ \\ ${ }^{1} 2$ nd Department of Internal Medicine, Faculty of Medicine, \\ Kyoto University, Sakyo-ku, Kyoto 606, Japan \\ ${ }^{2}$ Osaka Red Cross Hospital, Tennoji-ku, Osaka 543, Japan
}

\begin{abstract}
Pancreatic islet-cell antibodies (I.C.Ab.) were detected in the sera of 6 of 123 patients with insulin-dependent diabetes mellitus of recent onset, compared with only 2 positive results among the 434 control sera. The prevalence of humoral I.C.Ab. was strongly dependent on the duration of the diabetes, being 4 of 6 I.C.Ab. positive patients during the first year from diagnosis and falling to 2 of 6 I.C.Ab. positive patients at one to three years. Over four years from the time of diagnosis, there was no I.C.Ab. in the sera of the diabetics. Six I.C.Ab. positive in our group of 123 diabetic patients showed no association with any particular B locus antigen or DYT.
\end{abstract}

Considerable interest has been directed toward the possbility that autoimmunity may play an etiological role in a proportion of cases of insulin-dependent diabetes (IDD) (MacCuish et al., 1974a). A significant increase in the incidence of HLA-B8 and DW 3 has been reported in Caucasians with different autoimmune diseases, including IDD and Graves' disease (Grumet et al., 1974; McMichael et al., 1975). Furthermore pancreatic islet-cell antibodies (I.C.Ab.) in IDD correlated well with the duration and type of diabetes, coexistent autoimmune disease, and HLA type (Iravine et al., 1977). I.C.Ab. has been studied in British (Lendrum et al., 1976), Danish (Christy et al., 1976), Italian (Lendrum et al., 1975) and Spanish (Pujol-Borrel et al., 1978) populations and the frequency of positive reactions has been quite similar. We investigated I.C.Ab. and the relationship between HLA type and the frequency of I.C.Ab. in Japanese IDD.

Received June 17, 1979.

\section{Patients and Methods}

\section{Patients}

One hundred and thirty-one Japanese with juvenile-onset IDD so diagnosed by the age of onset below 30 and requirement of insulin and 101 agematched healthy controls were studied for HLA-A and B loci. Forty of these patients and 80 healthy controls were typed for HLA-DYT. Furthermore, one hundred and twenty-three of these patients were investigated for I.C.Ab.

Also, sixty-two patients were typed for HLA-A and $\mathrm{B}$ that had maturity-onset IDD, diagnosed by disease onset at age 30 and over, a rapid or gradual onset, nonobesity at onset, proneness to ketosis and absolute insulin dependence for therapy.

All these patients were attending a Kinki-region summer camp and the diabetic out-patient department of Osaka Red Cross Hospital.

\section{HLA Typing}

HLA typing was performed by a slight modification of the NIH lymphocytotoxicity test. All these antisera were used at the VIth International Histocompatibility Workshop in 1975 and some were prepared at the Blood Bank and Tissue Typing I aboratory of Tokai University Hospital.

HLA-D typing was also carried out by observing the reaction in the mixed lymphocyte reaction against 
homozygous stimulating cells. For the typing, we used DYT cells obtained from the same laboratory.

\section{I.C. $A b$.}

I.C.Ab. were detected by courtesy of Dr. W. J. Irvine in Edinburgh by the indirect immunofluorescence test using fresh post-mortem snap-frozen pancreatic tissue of blood-group $\mathrm{O}$, and antihuman IgG/FITC (Irvine et al., 1977).

\section{Results}

The results of HLA-B locus and DYT are show in Table 1. In 131 patients with IDD, the frequency of HLA-A2 was higher and HLA-AW19 was lower than in normal controls, but there was no statistical significance. In locus $A$, there was not significant relation to any antigen.

The frequency of HLA-BW54 was 35.9\% in 131 patients though the antigen was $8.9 \%$ in the 101 normal controls, therefore the frequency was significantly higher than in the normal controls. The frequency of HLA-B5 was $17.6 \%$ though the antigen was $36.7 \%$ in the normal controls. Thus, the frequency was significantly lower than in normal controls. On the other hand, the frequency of HLA-DYT was $55.0 \%$ in 40 patients though the antigen was $23.8 \%$ in the 80 normal controls. In IDD, the frequency of DYT was higher than normal controls, but such was not significant.

The prevalence of I.C.Ab. is shown in Table 2. I.C.Ab. were detected in the sera of 6 of 123 patients with IDD of recent onset, compared with only 2 positive results among the 434 control sera from non-Japanese. The prevalence of humoral I.C.Ab. was strongly dependent on the duration of the diabetes, being 4 of 6 I.C.Ab. positive patients during the first year from diagnosis and falling to 2 of 6 I.C.Ab. positive patients at one to three years. Four years or over from the time of diagnosis, there was no I.C.Ab. in the sera of the diabetics.

Table 2. Prevalence of I.C.Ab. in insulin dependent diabetics according to the duration of diabetes

\begin{tabular}{cccc}
\hline $\begin{array}{c}\text { Duration } \\
\text { of } \\
\text { diabetes }\end{array}$ & $\begin{array}{c}\text { No. of } \\
\text { patients } \\
\text { studied }\end{array}$ & $\begin{array}{c}\text { No. of patients } \\
\text { with pancreatic } \\
\text { islet cell anti- } \\
\text { bodies }\end{array}$ & Incidence \\
\hline$<1$ yr & 25 & 4 & $16 \%$ \\
$1-3$ & 24 & 2 & $8.3 \%$ \\
$4-5$ & 16 & 0 & - \\
$6-10$ & 42 & 0 & - \\
$>10$ yrs & 16 & 0 & $4.9 \%$ \\
Total & 123 & 6 & \\
\hline
\end{tabular}

Table 1. Phenotype frequency of HLA in Japanese diabetes mellitus in the Kinki disbrict

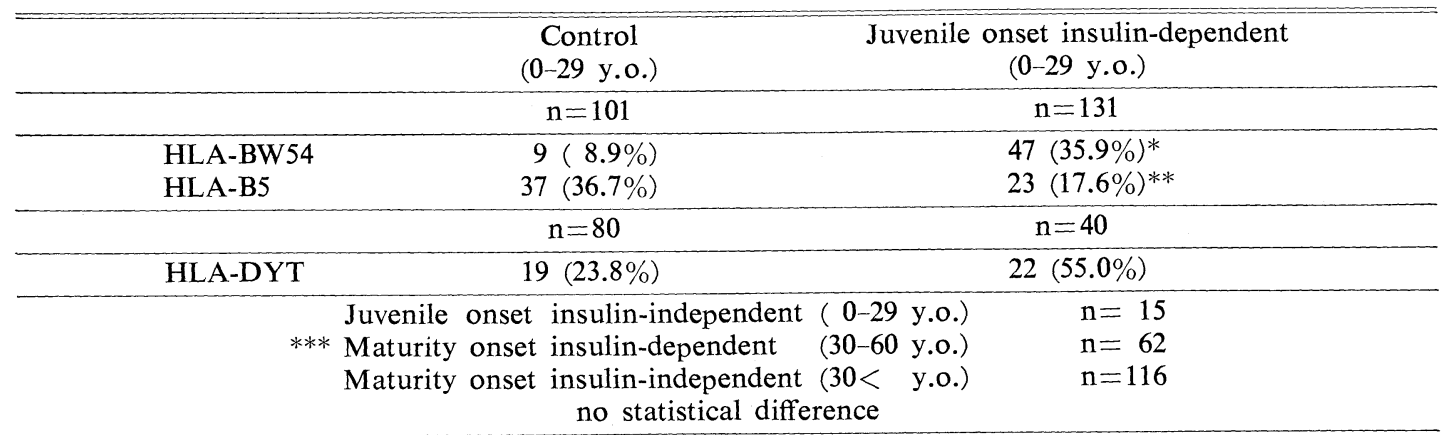

$\mathrm{n}=$ No. of patients studied.

*: Corrected $\mathrm{p}<0.0002$.

**: Corrected $\mathrm{p}<0.04$; negative association.

***: A characteristic of insulin-dependency is proneness to ketosis. 
We found that the associations between BW54 and the presence of I.C.Ab., positive cases of I.C.Ab. are few in Japanese patients with juvenile onset diabetes mellitus. In the six I.C.Ab. positive patients in our group of 123 diabetics there was no association with a particular B locus antigen or DYT.

\section{Discussion}

The etiology of diabetes mellitus is unknown, but there is little dout that genetical and enviromental factors are involved in the pathogenesis (Harvald et al., 1967; Frias and Rosenbloom 1973). In Caucasoid insulin-dependent diabetes, the correlation with autoimmunity is well established. Lymphocytic infiltration of the islets is found in juvenile diabetics who died shortly after the clinical onset of the disease (Lecompte and Legg, 1972). Evidence of an autoimmune explanation for islet-cell inflamation and damage has been sought for many years. Recent methodologic advances have resulted in frequent identification of I.C.Ab. in patients with newly diagnosed IDD by several investigators (Bottazzo et al., 1974; MacCuish et al., 1974).

Irvine et al., (1977) demonstrated that I.C.Ab. were most common in newly diagnosed IDD of recent onset and the prevalence of I.C.Ab. was strongly dependent on the duration of the diabetes. Lendrum et al. found these antibodies in the sera of 49 per cent of Italian IDD patients (1975) and of 38 per cent of British IDD patients (1976), Incidence of I.C.Ab. in other popu- lations were 55 per cent in Danish IDD patients (Christy et al., 1976) and 76 per cent in recent onset Spanish IDD patients (Pujor et al., 1978).

In contrast, the incidence of I.C.Ab. in the sera of our Japanese IDD was $4.9 \%$, being close to the insulin-independent diabetes or control levels in Caucasians. Since we used identical method of Irvine for detection of I.C.Ab., the marked differences. of I.C.Ab. incidence is not due to the difference in methodology but probably due to racial, dietary or geographical factors.

On the other hand, IDD has several HLA antigen associations. In addition to most common positive associations with B8, BW15, DW3 and DW4 (Irvine et al., 1977) (Table 3 ), there is also a negative association with B7 in Caucasoid. Cudworth and Woodraw (1976) considered that all these antigens are in linkage disequilibrium with a specific diabetogenic gene. In the Japanese, IDD is associated with BW54 (Table 1) (Wakisaka et al, 1976; Kawa et al., 1977; Nabeya et al., 1977; Okimoto et al., 1978) and not B8 thereby suggesting an ethinic variation of the genes in linkage disequilibrium. There is also a negative association with B5 (Table 1) (Kawa et al., 1977) and not with B7.

Furthermore, the studies has been made of the incidence of both $\mathrm{C}$ and $\mathrm{D}$ locus determinants and, more recently, of major histocompatibility system B cell encoded antigens DR. As is shown in Table 3 (Batchelor and Morris, 1978 ; Sasazuki et al., 1979), there is a significant association among DW3, DW4 and DRW3, DRW4 B cell antigens. In the Japanese, DYT rather than

Table 3. Insulin-dependent diabetes mellitus and HLA in two populations

\begin{tabular}{lllll}
\hline & B-locus & C-locus & D-locus & DR-locus \\
\hline $\begin{array}{l}\text { Caucasoids } \\
\text { Japanese }\end{array}$ & B8, B15 & CW3 & DW3, DW4 & DRW3, DRW4 \\
\hline
\end{tabular}

From Histocompatibility Testing, 1977.

* (Sasazuki et al., 1978). 
DW4 are increased (Sasazuki et al., 1979) (Table 1). However, DRW4 B cell antigen is similarly increased in the two populations. If these $B$ cell antigens appear to be the counterpart of at least some of the so-called Ia determinants of the mouse major histocompatibility system, $\mathrm{H}-2$ in general, the close association between DRW4 antigen and I.C.Ab. in both Caucasoid and Japanese IDD is of greater significance than that of already defined B or D locus antigens.

The increased frequency of HLA-B 8 was even more striking in diabetes in whom I.C.Ab. persisted for more 5 years (Irvine et at., 1977). However, among the Japanese IDD patients, there was no clear-cut correlation between the frequency of HLABW54 and/or DYT and I.C.Ab. positive patients. There is little evidence so far of persistent I.C.Ab. and of the occurence of clinical complication of other autoimmune diseases in Japanese juvenile-onset insulindependent diabetics. A weak autoimmune component and/or the absence of HLA-B8, DRW3 in Japanese juvenile-onset IDD may contribute to the lower prevalence of I.C.Ab. in our ethnic group. The significance of I.C.Ab. remains speculative although it has been postulated that such is the expression of islet damage initiated, perhaps, by a virus and perpepuated by autoimmune mechanism. However, the number of Japanese IDD patients with I.C.Ab. was too small to actually draw conclusion for correlation between the any HLA antigens and I.C.Ab. Thus, further detailed population and family studies are required to define the genetic relationship of HLA and I.C.A.b., especially as the DRW serology is still beeing developed.

\section{Acknowledgements}

HLA typing sera and DYT typing cells were kindly provided by Dr. Kimiyoshi Tsuji, Professor of the Blood Bank and Tissue Typing I aboratory, the Tokai University Hospital. Thanks are due to M. Ohara for assistance with the manuscript.

\section{References}

Bottazzo, G. F., Fluorin-Christensen and D. Doniach (1974). Lancet 2, 1279.

Batchelar, J. R. and P. J. Morris in Histocompatibility Testing 1977 (edited by W. F. Bodmer, J. R. Batchelor, J. G. Bodmer, H. Festenstein, P. J. Morris) Munksgaad, Copenhagen, p. 205 (1978).

Cudworth, A. G. and J. C. Woodrow (1976). Brit. Med. J. 2, 846.

Christy, M., J. Nerup, G. F. Bottazzo, D. Doniach, P. Platz, A. Svejgaad, L. P. Ryder and M. Tomsen (1976). Lancet 2, 142.

Frias, J. L. and A. L. Rosenbloom (1973). Metabolism 22, 355.

Grumet, F. C., R. Payne, J. Konishi and J. P. Kriss (1974). J. Clin. Endocrinol. Metab. 39, 115.

Harvald, B. (1967). Acta Med. Scand. Suppl. 476, 17. Irvine, W. J., C. J. McCallum, R. S. Gray, C. J. Campbell, L. J. P. Duncan, J. W. Farguhar, H. Vaughan and P. J. Morris (1977). Diabetes 26, 138.

Kawa, A., M. Nakazawa, S. Sakaguchi, S. Nakamura, Y. Kono, H. Kozeki and T. Kanehisa (1977). ibid. 26, 591.

LeCompte, Ph. M. and M. A. Legg (1972). ibid. 21, 762.

Lendrum, R., G. Walker and R. Gamble (1975). Lancet 1, 880.

Lendrum, R., G. Walker, A. G. Cudworth, C. Theophanides, D. A. Pyke, A. Bloom and D. R. Gamble (1976). Lancet 2, 1273.

MacCuish, A. C., E. W. Barnes, W. J. Irvine, L. J. P. Duncan (1974). ibid. 2, 1529.

McMichael, A., T. Sasazuki, R. Payne, F. C. Grumet, H. McDevitt and J. Kriss in Histocompatibility Testing 1975 (edited by F. Kissmeyer-Nielsen) Munksgaad, Copenhagen, p. 769 (1975).

Nabeya, N., K. Nagaoka, T. Sakurami, H. Imura, S. Kuno, K. Tsuji, Y. Nose (1977). Tonyobyo 20, 495. (In Japanese)

Okimoto, K., T. Juji, S. Ishiba, H. Maruyama, H. Tohyama and K. Kosaka (1978). Tissue Antigens 11, 418.

Pujor-Borrel, R., C. Richart, C. Martin, J. M. Martinez-Vazquez and G. F. Bottazzo (1978). Lancet $2,268$.

Sasazuki, T., Y. Kohno, I. Iwamoto, K. Kosaka, K. Okimoto, H. Maruyama, S. Ishiba, J. Konishi, Y. Takeda and S. Naito (1978). New Engl. J. Med. 298, 630.

Wakisaka, A., M. Aizawa, N. Matsuura, S. Nakagawa, E. Nakayama, K. Itakura, A. Okuno and Y. Wagatsuma (1976). Lancet 2, 970. 